\title{
CROP MODELING APPLICATIONS IN AGRICULTURAL WATER MANAGEMENT
}

\author{
I. Kisekka, K. C. DeJonge, L. Ma, J. Paz, K. Douglas-Mankin
}

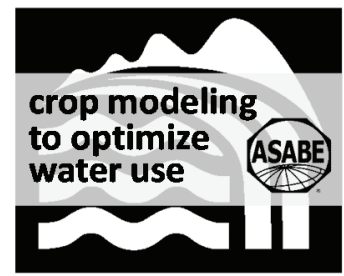

\begin{abstract}
This article introduces the fourteen articles that comprise the "Crop Modeling and Decision Support for Optimizing Use of Limited Water" collection. This collection was developed from a special session on crop modeling applications in agricultural water management held at the 2016 ASABE Annual International Meeting (AIM) in Orlando, Florida. In addition, other authors who were not able to attend the 2016 ASABE AIM were also invited to submit papers. The articles summarized in this introductory article demonstrate a wide array of applications in which crop models can be used to optimize agricultural water management. The following section titles indicate the topics covered in this collection: (1) evapotranspiration modeling (one article), (2) model development and parameterization (two articles), (3) application of crop models for irrigation scheduling (five articles), (4) coordinated water and nutrient management (one article), (5) soil water management (two articles), (6) risk assessment of water-limited irrigation management (one article), and (7) regional assessments of climate impact (two articles). Changing weather and climate, increasing population, and groundwater depletion will continue to stimulate innovations in agricultural water management, and crop models will play an important role in helping to optimize water use in agriculture.
\end{abstract}

Keywords. Agricultural water management, Crop modeling, Evapotranspiration, Irrigation, Irrigation scheduling.

$\mathrm{D}$ uring the 2016 ASABE Annual International Meeting (AIM) in Orlando, Florida, a special session was held on crop modeling applications in agricultural water management. Following the successful session at the 2016 ASABE AIM, speakers at the meeting as well as others were invited to submit full papers for publication consideration in a collection on "Crop Modeling and Decision Support for Optimizing Use of Limited Water." This introductory article summarizes the fourteen articles in this collection.

In many dry regions of the world, water is the major factor limiting agricultural production. Changing weather and climate, increasing population, and groundwater depletion are some of the factors exerting pressure on limited water

Submitted for review in October 2017 as manuscript number NRES 12693; approved for publication as part of the "Crop Modeling and Decision Support for Optimizing Use of Limited Water" collection by the Natural Resources \& Environmental Systems Community of ASABE in December 2017.

Mention of company or trade names is for description only and does not imply endorsement by the USDA. The USDA is an equal opportunity provider and employer.

The authors are Isaya Kisekka, ASABE Member, Assistant Professor, Departments of Land, Air, and Water Resources, and Biological and Agricultural Engineering, University of California, Davis, California; Kendall C. DeJonge, ASABE Member, Agricultural Engineer, USDAARS Water Management and Systems Research Unit, Fort Collins, Colorado; Liwang Ma, Research Scientist, USDA-ARS Rangeland Resources and Systems Research Unit, Fort Collins, Colorado; Joel Paz, ASABE Member, Associate Professor, Department of Agricultural and Biological Engineering, Mississippi State University, Mississippi State, Mississippi; Kyle Douglas-Mankin, ASABE Member, Supervisory Hydrologist, U.S. Geological Survey, Albuquerque, New Mexico. Corresponding author: Isaya Kisekka, 119 Veihmeyer Hall, University of California, Davis, CA; phone: 530-379-9549; e-mail: ikisekka@ucdavis.edu. supplies. Agricultural production, being a major user of water, is expected to use water efficiently to ensure sustainability (UNESCO, 2013). Cropping systems models provide a cost-effective framework for assessing water management strategies to optimize the use of limited water resources in both irrigated and dryland cropping systems. This collection highlights the state of the art in: (1) evapotranspiration modeling, (2) model development and parameterization, (3) application of crop models for irrigation scheduling, (4) coordinated water and nutrient management, (5) soil water management, (6) risk assessment of water-limited irrigation management, and (7) regional assessments of climate impact.

The studies presented in this article applied different crop simulation models, including AquaCrop (Steduto et al., 2009; Raes et al., 2009), DSSAT (Jones et al., 2003), EPIC (Williams, 1995), and RZWQM (Ahuja et al., 2000). This collection is intended to increase the visibility of this important topic among irrigation experts, agronomists, water managers, economists, farmers, and policymakers. The following sections summarize the main objectives, methods used, and key conclusions of each article in the collection.

\section{EVAPOTRANSPIRATION MODELING}

One article in the collection addresses improving evapotranspiration (ET) modeling in crop models, particularly in DSSAT (DeJonge and Thorp, 2017). While methods for estimating reference $\mathrm{ET}\left(\mathrm{ET}_{o}\right.$ or $\left.\mathrm{ET}_{r}\right)$ and subsequent crop ET $\left(\mathrm{ET}_{c}\right)$ via crop coefficient $\left(K_{c}\right)$ and dual crop coefficient $\left(K_{c b}, K_{e}\right)$ methods have been standardized since 2005 and 1998 respectively, the current version of the DSSAT cropping system model (CSM) has not been updated to fully implement these methods. To close this gap, DeJonge and 
Thorp (2017) made two major enhancements to the model's ET routines: (1) addition of the ASCE Standardized Reference Evapotranspiration Equation so that both grass and alfalfa reference ET were properly calculated using the most recent reference ET standard, and (2) addition of the FAO-56 dual crop coefficient approach to determine potential ET, which combined an evaporative coefficient $\left(K_{e}\right)$ for potential evaporation with a dynamic basal crop coefficient $\left(K_{c b}\right)$ for potential transpiration as a function of simulated leaf area index.

Previously published data sets for maize in Colorado (five years) and cotton in Arizona (seven years) were used to parameterize the model. DeJonge and Thorp (2017) compared simulated $\mathrm{ET}_{o}$ to outputs from Ref-ET software (Allen, 2000) and crop coefficients determined by three different approaches: the current approach $\left(K_{c S}\right)$ as implemented in DSSAT, a previously published adjustment to the model's $K_{c}$ equation ( $K_{c d}$; DeJonge et al., 2012), and a new dual $K_{c}$ approach that follows FAO-56 explicitly $\left(K_{c b}\right)$, presented by DeJonge and Thorp (2017). Their results showed that crop coefficient simulations with the new $\mathrm{ET}_{o^{-}}$ $K_{c b}$ method better mimicked theoretical behavior, including spikes in the soil evaporation coefficient $\left(K_{e}\right)$ due to irrigation and rainfall events and the basal crop coefficient response associated with simulated crop growth. Simulated $\mathrm{ET}_{c}$ and crop yield with the new $\mathrm{ET}_{o}-K_{c b}$ method were up to $4 \%$ higher and $28 \%$ lower for cotton and up to $13 \%$ higher and $26 \%$ lower for maize, respectively, than that for the current $\mathrm{ET}_{o}-K_{c s}$ method, indicating that the seasonal $\mathrm{ET}_{c}$ effects were minimal while crop yield effects were more substantial. Use of FAO-56 concepts and current ET standards in DSSAT-CSM demonstrated a well-accepted ET benchmark to guide assessment of other ET methods in the model and made the model much more conceptually similar to approaches traditionally used by irrigation and ET specialists.

\section{Model DeVelopment and PARAmeterization}

Two articles in the collection discuss the importance of model parameterization and the need for high-quality experimental data in model calibration and validation: Espadafor et al. (2017) and Anar et al. (2017). Even for deterministic or process-based models, calibration and validation using high-quality experimental datasets is a basic requirement before the models should be used to assess management strategies. Quality data such as ET measurements are not always readily available due to the high cost of equipment (e.g., large weighing lysimeters), but they should be fully utilized when available.

Espadafor et al. (2017) calibrated the FAO crop simulation model AquaCrop and validated it for dry beans (Phaseolus vulgaris L.) using data from experiments performed 40 years ago at Davis, California. Despite the age of the dataset, it was of high quality. Espadafor et al. (2017) used a set of parameters derived from the calibration with one irrigation experiment to validate the model using five experiments carried out in 1977 and 1978 that had treatments vastly differing in irrigation depth and frequency. They reported that crop yield predictions over a wide range of values (from $<1 \mathrm{t} \mathrm{ha}^{-1}$ to $3.5 \mathrm{t} \mathrm{ha}^{-1}$ ) were very good, with
RMSE of $0.16 \mathrm{tha}^{-1}$. Seasonal ET was also accurately predicted by the model, as evidenced by comparing the lysimeter-measured ET of $489 \mathrm{~mm}$ against the simulated ET of $501 \mathrm{~mm}$. Canopy cover and biomass changes over time were adequately simulated as well. Espadafor et al. (2017) reported that total soil water extraction was well simulated, but simulated soil water distribution with depth differed from measured values in the dryland treatment, which indicates opportunities to improve soil water simulation algorithms in AquaCrop. Espadafor et al. (2017) concluded that their calibrated and validated AquaCrop model can be used for simulation of dry beans in different environments.

Anar et al. (2017) parameterized, calibrated, and validated the CERES sugarbeet model to simulate the effects of sugarbeet production on soil and water quality in North Dakota. They emphasized the need for sensitivity analysis to identify and determine parameters to which model output was most sensitive.

\section{ApPlication OF Crop MOdels fOR IRRIGATION SCHEDULING}

Five articles in the collection discuss applications of crop models for irrigation scheduling or irrigation water management: Linker and Kisekka (2017), Thorp et al. (2017), Liu et al. (2017), Fang et al. (2017a), and Tang et al. (2018). Irrigation scheduling can be implemented based on monitoring soil and plant water status or by using the ET-based approach that involves scaling the potential or reference ET using a crop coefficient. If implemented properly, all of these approaches can improve irrigation scheduling, especially under adequate water supply. However, most of these approaches do not provide direct feedback on how irrigation management decisions impact seasonal crop yields. The studies summarized in this collection demonstrate how crop simulation models can be a useful tool for implementing tactical irrigation scheduling and for providing feedback on how irrigation scheduling decisions might impact crop yield. Most of the prior studies on optimizing irrigation scheduling using crop simulation models focused on retrospective evaluation of irrigation scheduling options based on experimental data and long-term weather data (Saseendran et al., 2008; DeJonge et al., 2011; Kisekka et al., 2016). Very little work is documented in the literature on using crop simulation models for real-time tactical in-season irrigation scheduling. Some of the newer research on the use of crop simulation models for tactical inseason irrigation scheduling was reported by Thorp et al. (2017) and Linker and Kisekka (2017).

Thorp et al. (2017) compared the CSM-CROPGROCotton model (with recently updated ET routines; DeJonge and Thorp, 2017) to a well-tested FAO-56 irrigation scheduling spreadsheet by: (1) using both tools to schedule cotton irrigation during 2014 and 2015 in central Arizona, and (2) conducting a post hoc simulation study to further compare the outputs from these tools. Irrigation schedules were developed on a weekly basis and administered via an overhead lateral-move sprinkler irrigation system. While total seasonal irrigation amounts were similar between the two scheduling tools, the crop model recommended more water during anthesis and less during the early season, which led 
to higher cotton fiber yield in both seasons $(\mathrm{p}<0.05)$. The tools calculated cumulative evapotranspiration similarly, with RMSE less than 13\%; however, FAO-56 crop coefficient plots demonstrated subtle differences in daily ET calculations. Through field verification and thorough post hoc data analysis, the results demonstrated that the CSMCROPGRO-Cotton model with updated FAO-56 ET routines could match or exceed the accuracy and capability of an FAO-56 spreadsheet tool for cotton water use calculations and irrigation scheduling. Thorp et al. (2017) noted that their study exhibited real-world application of crop models for in situ water management, a task rarely demonstrated in practice.

In many areas where water supplies are not sufficient to meet full crop water needs, deficit irrigation is practiced (e.g., the Central Valley of California and the Ogallala aquifer of the U.S. High Plains). Scheduling deficit irrigation is more complicated compared to scheduling full irrigation because it requires knowledge of crop yield response to water and effects at different growth stages. Linker and Kisekka (2017) demonstrated the potential of model-based optimization of deficit irrigation for determining adequate soil water depletion levels that minimize yield penalty. CERES-Maize was used as a surrogate crop (in the real world, this would be the crop in the field), while AquaCrop was used in a multi-objective optimization procedure that determined the optimal water depletion levels in the soil profile throughout the growing season. A multi-objective optimization framework was used to determine several combinations of optimal water depletion levels based on ten years of historical weather, and the soil water depletions were tested using an additional fifty years of historical weather. The results showed that despite uncertainty in the crop model predictions (using AquaCrop) and the weather forecast, soil water depletion thresholds derived through multi-objective irrigation scheduling optimization were a useful tool to guide irrigation scheduling. Linker and Kisekka (2017) recommended further research into the possibility of using purely model-based approaches as an attractive alternative to non-trivial continuous soil water measurements in scheduling deficit irrigation.

In another application, Liu et al. (2017) used the water stress factor computed by DSSAT embedded in RZWQM2 to trigger irrigation. They calibrated and validated the RZWQM2-DSSAT model against soil moisture, cotton yield, and development stage data collected from 2006 to 2013 in a flood-irrigated cotton field located in an extremely dry oasis in Cele, Xinjiang, China. The simulated water balance was analyzed to determine the actual crop water consumption, crop water requirements, and seepage loss. An optimal irrigation scheduling scheme was developed using RZWQM2 by averting crop water stress from planting to $90 \%$ open boll. On average, Liu et al. (2017) recorded water savings of $4.9 \%$ and an annual crop yield increase of $527 \mathrm{~kg} \mathrm{ha}^{-1}(16.3 \%)$. They reported that RZWQM2 was suitable for simulating soil hydrology and crop development in an agricultural system implemented in an extremely dry climate. They concluded that scheduling of irrigation using a water stress-based approach can be used to optimize irrigation water use in cotton production.
Fang et al. (2017a) also used RZWQM with a 57-year weather dataset from the Yucheng Experimental Station in the North China Plain to explore crop responses to ETbased irrigation scheduling and identify the most suitable ET-based irrigation schedules in the area. Irrigation amount was determined by taking a percentage of potential crop ET $\left(40 \%, 60 \%, 80 \%\right.$, or $\left.100 \% \mathrm{ET}_{c}\right)$ at various growth periods of wheat and maize, subject to various levels of seasonal water limits. In general, wheat was more responsive to irrigation than maize, while greater influence of weather variation on maize than on wheat was simulated. Wheat generally showed the highest water use efficiency (WUE) and yield with high target $\mathrm{ET}_{c}$ levels between green-up and flowering. Maize saw minimal effects of low $\mathrm{ET}_{c}$ after silking, an effect due to high seasonal rainfall, but the authors still recommend irrigation of at least $60 \% \mathrm{ET}_{c}$ before silking. These results could be used as guidelines for precision irrigation along with real-time weather information.

Tang et al. (2018) applied the RZWQM model to evaluate supplemental irrigation in the Mississippi Delta, a humid region where irrigation has contributed to depletion of groundwater levels. Their study objectives were to determine rain water deficit and crop water requirements of maize, soybean, and cotton. Tang et al. (2018) reported that on average $\mathrm{ET}_{c}$ of soybean, maize, and cotton was 546, 588 , and $552 \mathrm{~mm}$, respectively. They noted that rainfall was insufficient to meet full crop water requirements of soybean, maize, and cotton starting in the 6th, 8th, and 7th weeks after planting, which resulted in rainfall deficits (the difference between $\mathrm{ET}_{c}$ and rainfall) of 262, 237, and $228 \mathrm{~mm}$, respectively, based on RZWQM simulations and 100 years of historical climatic data. Their findings could be used to improve irrigation scheduling, water resources planning, and cropping system design in the Mississippi Delta.

\section{COORDINATED WATER AND NUTRIENT \\ MANAGEMENT}

One article in the collection addresses the topic of coordinated water and nutrient management using the RZWQM (Fang et al., 2017b). Crop models can provide a costeffective framework for evaluating coordinated water and nutrient management in agricultural systems. Crop nitrogen (N) uptake is a critical component affecting crop growth and soil $\mathrm{N}$ balance, such as soil residual $\mathrm{N}$ and $\mathrm{N}$ losses to the environment. Crop models can benefit from better representation of new concepts in soil and crop processes. For example, the concept of critical $\mathrm{N}$ concentrations (TCNP) as the minimum $\mathrm{N}$ concentration in aboveground biomass (AGB) required for maximizing growth is an important indicator of better crop $\mathrm{N}$ management. New maize hybrids have lower critical aboveground biomass $\mathrm{N}$ concentration and grain $\mathrm{N}$ concentration (GNC) compared to older hybrids, but this trend has not yet been incorporated into crop models. Fang et al. (2017b) evaluated a new algorithm for calculating TCNP and GNC in the CERES-Maize model as implemented in RZWQM2 for predicting crop N concentration and $\mathrm{N}$ uptake for a new maize hybrid. Maize was irrigated to meet a certain percentage ( $40 \%$ to $100 \%)$ of ET demand at both the vegetative and reproductive stages in 
2012 and 2013 in Greeley, Colorado. The original model showed little or no response of aboveground biomass and grain $\mathrm{N}$ concentration to the irrigation treatments and overpredicted crop $\mathrm{N}$ concentration and $\mathrm{N}$ uptake for the new maize hybrid. Fang et al. (2017b) adjusted coefficients in the original TCNP and GNC algorithms, which effectively reduced the oversimulation of crop $\mathrm{N}$ concentration but produced less improvement in response to the irrigation treatments. They also developed new algorithms for calculating TCNP and GNC that simulated lower aboveground biomass and grain $\mathrm{N}$ concentrations than the original algorithm and that significantly improved responses to the irrigation treatments.

\section{SOIL WATER MANAGEMENT}

Two articles in the collection discuss the importance of soil water management in crop modeling. Adhikari et al. (2017) evaluated the effect on soil water of using winter wheat as a cover crop, while Whitbread et al. (2017) explored the use of field-measured soil water properties versus laboratory measurements in calibrating crop models. Soil water is the major limiting factor for crop production in semi-arid and arid agricultural regions. Crop modeling provides a cost-effective and integrated framework for assessing management strategies (e.g., use of cover crops, crop rotations, etc.) that improve soil water storage and enhance crop yields. Adhikari et al. (2017) used the DSSAT model to evaluate winter wheat as a cover crop in cotton production. They simulated cover crops in both irrigated and dryland cotton rotations from 2011-2015 in the Texas Rolling Plains. The calibrated model was then used to simulate the long-term effects of a cover crop on cotton production using weather data from 2001-2015. The main finding of their study was that there was no substantial reduction in average seed cotton yield and soil water due to growing winter wheat as a cover crop. However, there was higher interannual variation in cotton yield under dryland conditions than under irrigated conditions. Annual cotton yield variation after the cover crop was affected more by the soil and weather conditions at the time of cover crop harvest than by cover crop water use.

In another application of crop modeling to study soil water in low-rainfall cropping systems, Whitbread et al. (2017) used the APSIM model and experimental measurements from the Mallee region of South Australia and New South Wales to assess soil water storage in a rainfed cropping system. They used long-term field datasets collected from experiments in the Mallee region, including multilayer soil water measurements made with frequency domain reflectometry (FDR) probes and crop performance data monitored from fallow-wheat, continuous cereal, or break crop-cereal rotations. They reported that field estimates of crop lower limit or drained upper limit were more reliable than lab-based estimates despite the fact that the plant-available water capacity (PAWC) did not substantially differ between the methods. Of critical importance for management is the prediction of soil water content at key decision points in the season. Using APSIM to simulate plant-available water over the three-year rotations, they found that predicted soil water was within $7 \mathrm{~mm}$ (PAWC
64 to $99 \mathrm{~mm}$ ) of the measured data across all sowing events and rotations. They reported that simulated $(n=46)$ wheat grain production resulted in an RMSE of $492 \mathrm{~kg} \mathrm{ha}^{-1}$, which was only marginally smaller than that of other field studies that derived soil water limits from less detailed methods. The main finding of Whitbread et al. (2017) was that using field-measured or derived soil water storage and hydraulic properties helped improve the parametrization of the APSIM model.

\section{RISK ASSESSMENT OF WATER-LIMITED IRRIGATION MANAGEMENT}

One article in the collection addresses the topic of risk assessment in relation to irrigation water management using the AquaCrop model and risk aversion assessment techniques (Wibowo et al., 2017). Under limited water, farmers are faced with non-trivial optimization of multiple objectives (e.g., maximization of net profit, optimization of water use through maximization of water productivity, and minimization of risk to net returns). Wibowo et al. (2017) explored this concept using a modeling framework to assess the optimal adjustment along the intensive (i.e., changes in seasonal irrigation depth) and extensive (i.e., changes in the irrigated area) margins. Their empirical application used AquaCrop to simulate corn yields with historical weather in southwest Kansas under a large number of potential irrigation strategies. They show that risk aversion significantly increases total water use, especially for low and medium well capacities. While farmers decreased the irrigated area due to risk aversion, increases in water use occurred because it was optimal to increase the seasonal irrigation depth to reduce production risk. Counterintuitively, risk aversion had a smaller impact on water use for a soil with lower water holding capacity because optimal irrigation increases under risk neutrality for soils with a lower water holding capacity. These results highlight the importance of accounting for risk aversion when estimating the optimal irrigation management strategies and show that the impact of risk aversion differs significantly by well capacity and soil type.

\section{Regional ASSESSMENTS OF Climate IMPACT}

Two articles in the collection discuss crop model applications on large spatial scales: Tatsumi (2017) and Sharda et al. (2017). Crop models linked with geographic information systems (GIS) and general circulation models (GCMs) are useful tools for conducting regional assessments on the impacts of climate change, on the implementation of mitigation practices, and for the support of policy making.

Tatsumi (2017) conducted a detailed analysis of the effects of climate change and increased carbon dioxide $\left(\mathrm{CO}_{2}\right)$ concentrations on maize yield across the U.S. using the EPIC (Williams, 1995) crop model and outputs from multiple general circulation models (multi-GCMs). Maize yield was simulated for 1999-2010, for the 2050s (average for 2041-2060), and for the 2070s (average for 2061-2080) under the Representative Concentration Pathways 8.5 (RCP8.5) climate scenario. Tatsumi (2017) reported a 
shortening of the growing period, decreased WUE in almost all regions, and increased ET during the growing period in almost all regions except the southern U.S. Using multi-GCMs, the simulations under the RCP8.5 climate scenario resulted in negative effects of climate change on yield in almost all regions during both future periods. Especially strong negative impacts were reported south of latitude $40^{\circ} \mathrm{N}$ due to less optimal growing conditions. On the other hand, there were relatively smaller negative impacts in high latitude regions (approximately north of latitude $40^{\circ} \mathrm{N}$ ) due to more optimal growing conditions because of larger temperature changes and less water stress compared to low and mid-latitude regions. Tatsumi (2017) concluded that higher $\mathrm{CO}_{2}$ concentrations have the potential to increase maize yield. $\mathrm{CO}_{2}$ effects resulted in an approximately $0.04 \%$ to $0.05 \%$ increase in yield per $1 \mathrm{ppm}$ increase in $\mathrm{CO}_{2}$ concentration under the RCP8.5 climate scenario, but the negative impacts of increased temperatures fully outweighed the $\mathrm{CO}_{2}$-fertilization effects.

The simulation of crops such as maize, which are extensively grown in the U.S. and around the world, can be effectively implemented to predict the risk to crop production due to soil and climate variability. In another regional assessment study, Sharda et al. (2017) applied DSSAT to simulate the growth, development, and grain yield of maize for the top ten producing counties in Alabama under rainfed conditions during dry and wet El Niño Southern Oscillation (ENSO) years. Maize yield simulations were compared for one prominent agricultural soil in each county, for the top three prominent agricultural soils in each county, and for spatially distributed SSURGO soils in each of the selected counties. Spatial variability of the model responses was shown to be strongly affected by the soil variability within the study region when simulating yields for the 30year study period. Sharda et al. (2017) reported that using SSURGO soils as input to simulate maize yield was statistically better for almost all counties as compared to using the most prominent soil or the top three agricultural soils in each county, which resulted in higher overestimation of yield. One of the main outputs from this study was the maps that provide a powerful visual of the spatial variability of maize yield attributable to soil variability. These maps provide us the ability to look at the yield in different areas of a field and determine how soils and soil properties impact production. Sharda et al. (2017) suggested the option of increasing maize yield by assigning production to high-yielding soils in a particular county in the region.

\section{CONCLUSIONS}

Advances in crop modeling and their application in various aspects of agricultural water management present opportunities for cost-effective and systems assessment of water use in agriculture. Application of crop models in agricultural water management is certainly not limited to the fourteen articles included in this collection; in fact, some of the papers presented at the special session on crop modeling and water management at the 2016 ASABE AIM in Orlando that formed the basis for this collection addressed topics such as gene-based modeling, multi-year water allocation optimization, drought and aridity, and novel parameter estimation methodologies. The presented papers showed the advances in crop modeling focused on agricultural water management and the increasing acceptance of this approach. Changing weather and climate, increasing population, and groundwater depletion will continue to stimulate innovations in agricultural water management, and crop models will likely play a critical role in helping to optimize water use in agriculture.

\section{ACKNOWLEDGEMENTS}

This article introduces the fourteen articles in the "Crop Modeling and Decision Support for Optimizing Use of Limited Water" collection in this issue of Transactions of the ASABE. The organizers of this collection would like to thank the authors for their contributions to the research literature as well as the ASABE publications staff, associate editor, and reviewers for their contributions to and timely management of the review process.

\section{REFERENCES}

Adhikari, P., Omani, N., Ale, S., DeLaune, P. B., Thorp, K. R., Barnes, E. M., \& Hoogenboom, G. (2017). Simulated effects of winter wheat cover crop on cotton production systems of the Texas Rolling Plains. Trans. ASABE, 60(6), 2083-2096. https://doi.org/10.13031/trans.12272

Ahuja, L. R., Rojas, K. W., Hanson, J. D., Shaffer, M. J., \& Ma, L. (2000). The root zone water quality model. Highlands Ranch, CO: Water Resources Publications.

Allen, R. G. (2000). REF-ET: Reference evapotranspiration calculation software for FAO and ASCE standardized equations. Ver. 2 for Windows. Kimberly, ID: University of Idaho Research and Extension Center.

Anar, M. J., Lin, Z., Ma, L., Bartling, P., Teboh, J. M., \& Ostlie, M. (2017). Analysis of parameter sensitivity and identifiability of Root Zone Water Quality Model (RZWQM) for dryland sugarbeet modeling. Trans. ASABE, 60(6), 1995-2010. https://doi.org/10.13031/trans.12313

DeJonge, K. C., \& Thorp, K. R. (2017). Implementing standardized reference evapotranspiration and dual crop coefficient approach in the DSSAT cropping system model. Trans. ASABE, 60(6), 1965-1981. https://doi.org/10.13031/trans.12321

DeJonge, K. C., Andales, A. A., Ascough II, J. C., \& Hansen, N. C. (2011). Modeling of full and limited irrigation scenarios for corn in a semiarid environment. Trans. ASABE, 54(2), 481-492. https://doi.org/10.13031/2013.36451

DeJonge, K. C., Ascough II, J. C., Andales, A. A., Hansen, N. C., Garcia, L. A., \& Arabi, M. (2012). Improving evapotranspiration simulations in the CERES-Maize model under limited irrigation. Agric. Water Mgmt., 115, 92-103. https://doi.org/10.1016/j.agwat.2012.08.013

Espadafor, M., Couto, L., Resende, M., Henderson, D. W., GarciaVila, M., \& Fereres, E. (2017). Simulation of the responses of dry beans (Phaseolus vulgaris L.) to irrigation. Trans. ASABE, 60(6), 1983-1994. https://doi.org/10.13031/trans.12386

Fang, Q. X., Ma, L., Qi, Z., Shen, Y. J., He, L., Xu, S. H., ... Yu, Q. (2017a). Optimizing ET-based irrigation scheduling for wheat and maize with water constraints. Trans. ASABE, 60(6), 20532065. https://doi.org/10.13031/trans.12363

Fang, Q. X., Ma, L., Trout, T. J., Comas, L. H., DeJonge, K. C., Ahuja, L. R., ... Malone, R. W. (2017b). Modeling N 
concentration and uptake for maize hybrid under growth stagebased deficit irrigations. Trans. ASABE, 60(6), 2067-2081. https://doi.org/10.13031/trans.12405

Jones, J. W., Hoogenboom, G., Porter, C. H., Boote, K. J., Batchelor, W. D., Hunt, L. A., ... Ritchie, J. T. (2003). The DSSAT cropping system model. European J. Agron., 18(3), 235-265. https://doi.org/10.1016/S1161-0301(02)00107-7

Kisekka, I., Aguilar, J., Rogers, D., Holman, J., OBrien, D., \& Klocke, N. (2016). Assessing deficit irrigation strategies for corn using simulation. Trans. ASABE, 59(1), 303-317. https://doi.org/10.13031/trans.59.11206

Linker, R., \& Kisekka, I. (2017). Model-based deficit irrigation of maize in Kansas. Trans. ASABE, 60(6), 2011-2022. https://doi.org/10.13031/trans.12341

Liu, C., Qi, Z., Gu, Z., Gui, D., \& Zeng, F. (2017). Optimizing irrigation rates for cotton production in an extremely arid area using RZWQM2 simulated water stress. Trans. ASABE, 60(6), 2041-2052. https://doi.org/10.13031/trans. 12365

Raes, D., Steduto, P., Hsiao, T. C., \& Fereres, E. (2009). AquaCrop: The FAO crop model to simulate yield response to water: II. Main algorithms and software description. Agron. J., 101(3), 438-447. https://doi.org/10.2134/agronj2008.0140s

Saseendran, S. A., Ahuja, L. R., Nielsen, D. C., Trout, T. J., \& Ma, L. (2008). Use of crop simulation models to evaluate limited irrigation management options for corn in a semiarid environment. Water Resour. Res., 44(7),. https://doi.org/10.1029/2007WR006181

Sharda, V., Handyside, C., Chaves, B., McNider, R. T., \& Hoogenboom, G. (2017). The impact of spatial soil variability on the simulation of regional maize yield. Trans. ASABE, 60(6), 2137-2148. https://doi.org/10.13031/trans.12374
Steduto, P., Hsiao, T. C., Raes, D., \& Fereres, E. (2009). AquaCrop: The FAO crop model to simulate yield response to water: I. Concepts and underlying principles. Agron. J., 101(3), 426-437. https://doi.org/10.2134/agronj2008.0139s

Tang, Q., Feng, G., Fisher, D., Ouyang, Y., Jenkins, J., \& Adeli, A. (2018). Rain water deficit and irrigation demand of major row crops determined by RZWQM2 model based on long-term weather conditions in the Mississippi Delta. Trans. ASABE, 61(1), in press. https://doi.org/10.13031/trans.12397

Tatsumi, K. (2017). Integrated assessment of climate change impacts on corn yield in the U.S. using a crop model. Trans. $A S A B E$, 60(6), 2123-2136. https://doi.org/10.13031/trans.12314

Thorp, K. R., Hunsaker, D. J., Bronson, K. F., Andrade-Sanchez, P., \& Barnes, E. M. (2017). Cotton irrigation scheduling using a crop growth model and FAO-56 methods: Field and simulation studies. Trans. ASABE, 60(6), 2023-2039. https://doi.org/10.13031/trans.12323

UNESCO. (2013). Water cooperation 2013. Paris, France: United Nations Educational, Scientific, and Cultural Organization.

Whitbread, A. M., Hoffmann, M. P., Davoren, C. W., Mowat, D., \& Baldock, J. A. (2017). Measuring and modeling the water balance in low-rainfall cropping systems. Trans. ASABE, 60(6), 2097-2110. https://doi.org/10.13031/trans.12581

Wibowo, R. P., Hendricks, N. P., Kisekka, I., \& Araya, A. (2017). Using a crop simulation model to understand the impact of risk aversion on optimal irrigation management. Trans. ASABE, 60(6), 2111-2122. https://doi.org/10.13031/trans.12320

Williams, J. R. (1995). The EPIC. In V. P. Singh (Ed.), Computer models of watershed hydrology (pp. 909-1000). Highlands Ranch, CO: Water Resources Publications. 